Article

\title{
Experimental and Theoretical Study on the Critical Breaking Velocity of Marine Natural Gas Hydrate Sediments Breaking by Water Jet
}

\author{
Leizhen Wang and Guorong Wang * \\ School of Mechanical Engineering, Southwest Petroleum University, Chengdu 610500, Sichuan, China; \\ 201511000057@stu.swpu.edu.cn \\ * Correspondence: 200331010023@swpu.edu.cn; Tel.: +86-13981938089
}

Received: 14 February 2020; Accepted: 1 April 2020; Published: 4 April 2020

\begin{abstract}
Water jet technology is a key technology in the marine natural gas hydrate (NGH) solid fluidization mining method. As an important parameter in water jet breaking NGH sediments technology, the critical breaking velocity of NGH sediments is unknown. In the present research, an orthogonal design experiment is carried out to study the critical velocity of NGH breakage by water jet, using frozen soil and sand as experimental samples. First, the time it takes to reach maximum NGH breaking depth is determined. Then, ultimate breaking distance is studied with respect to the NGH saturation, jet pressure, and nozzle diameter. Following that, the variation of critical velocity with NGH saturation is analyzed. Eventually, a formula to calculate the critical velocity for marine NGH breakage by water jet process is established, and the undetermined coefficient $(\eta)$ in the formula is calibrated with the experiment data. The results show that the ultimate breaking distance is mostly achieved within $63 \mathrm{~s}$. The three experimental factors in order of the effect on the ultimate breaking depth (from high to low) are NGH saturation, jet pressure, and nozzle diameter. The critical velocities for marine NGH breakage corresponding to the NGH saturations of $20 \%, 40, \%, 6 \%$, and $80 \%$ are $5.71 \mathrm{~m} / \mathrm{s}, 7.14 \mathrm{~m} / \mathrm{s}, 9.60 \mathrm{~m} / \mathrm{s}$, and $10.85 \mathrm{~m} / \mathrm{s}$, respectively. The undetermined coefficient $\eta$ in critical velocity formula is $1.44 \mathrm{~m} / \mathrm{s}$.
\end{abstract}

Keywords: natural gas hydrate; critical velocity; solid fluidization method; water jet; ultimate breaking distance

\section{Introduction}

Natural gas hydrate (NGH), also named as "Flammable Ice", is considered to be an alternative clean energy source in the 21st century because of its huge reserves [1]. The total amount of NGH resources in the world is about $3 \times 10^{15} \mathrm{~m}^{3}$, most of which is stored in the ocean [2-4]. According to the types of accumulation, marine NGH can be divided into four types: the sandstone NGH reservoir, non-sandstone NGH reservoir, seafloor mounds NGH reservoir, and disseminated NGH reservoir [5]. Sandstone NGH reservoirs, which have a relatively high porosity and are easy to exploit, are usually selected for production tests [6-8]. Disseminated NGH reservoirs, although accounting for more than $90 \%$ of the total NGH reserves, are difficult to exploit with the current technology because of low permeability [9]. The NGH resources in the South China Sea are about 85 trillion $\mathrm{m}^{3}$ [10]. However, they belong to the disseminated NGH reservoir type, and its matrix is mainly composed of clay and silty sand. The characteristics of hydrate in the South China Sea can be summarized as low permeability, shallow burial, and poor cementation. Although so many methods, such as heat injection, depressurization, chemical injection, carbon dioxide replacement, and solid fluidization, have been proposed, and are expected to be used in hydrate production [11-14]. However, for marine 
disseminated NGH reservoirs, only the depressurization method and the solid fluidization method have been technically verified by the offshore production test in the South China Sea in 2017 [14,15]. In the process of the production test with depressurization method, hydraulic slotting technology is used to solve the problem of the low permeability of the disseminated NGH reservoir [16]. The solid fluidization method is a new NGH production method, and its process is shown in Figure 1 [17]. First, a small borehole is drilled with coiled tubing. Then the NGH sediment around the borehole is broken into fine particles by water jet technology. After mixing with water, particles of hydrate, clay, and sand form slurry. Under the action of in situ separator, clay, and sand particles are separated and backfilled. Hydrate particles are transported to the ocean surface through the riser for further treatment [18].

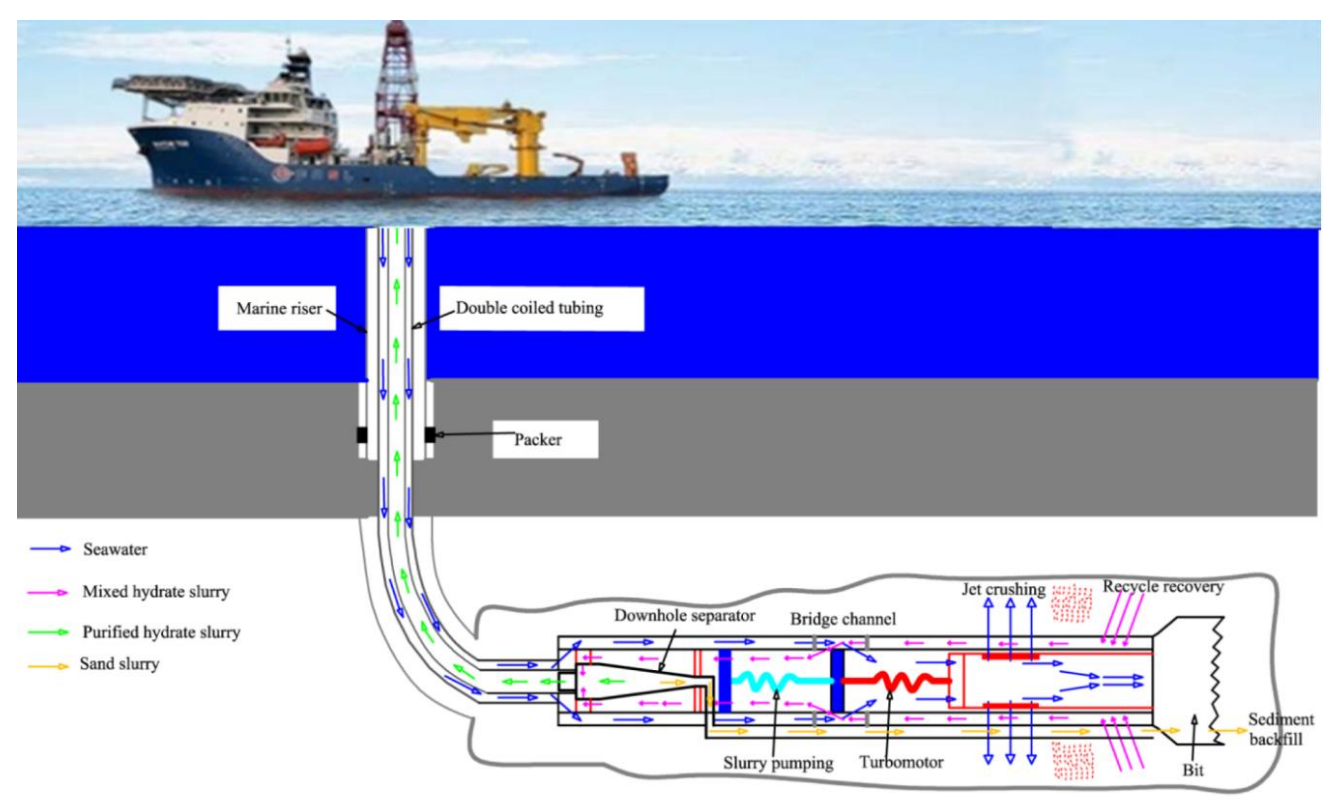

Figure 1. The exploitation process of natural gas hydrate (NGH) with the solid fluidization method. (Adapted from Qiu [17])

It can be seen that the technology of water jet breaking NGH is one of the core technologies of both the depressurization method and the solid fluidization method. Therefore, the technology of water jet breaking NGH has attracted the attention of some scholars. Pan [19] studied the effect of jet velocity on erosion depth and volume of NGH sediment by numerical simulation. Chen [20] studied the water jet erosion efficiency of hydrate-bearing sediment in the South China Sea under various work parameters, such as jet velocity, standoff distance, and nozzle diameter with the Arbitrary Lagrangian-Eulerian (ALE) method. Yang [21] carried out an experiment about the breaking of NGH with water jet. The influence of target distance, NGH saturation, and jet flow rate on the breaking depth is studied. Wang $[22,23]$ carried out experiments of NGH breaking by water jet with frozen soil as experimental sample, developed a water jet mining tool, and optimized the water jetting parameters of the NGH production test in South China Sea. Wang [24] studied the effect of moving speed of mine head, jet flow rate, and jet action number on the jet breaking effect on four aspects: borehole shape, borehole diameter, breaking efficiency, and slurry concentration. The critical breaking velocity is an important parameter for evaluating the object's erodibility in water jet breaking technology. It means that only when the jet velocity on the contact surface of the jet and the object is higher than a certain value, will the object be damaged. In addition to evaluating the object's erodibility, the critical speed is also a key parameter to predict the breaking rate. However, the critical breaking velocity of NGH sediment under the action of the water jet is still unknown.

In this research, an orthogonal design experimental study of the critical velocity of NGH sediment under the action of water jet was carried out using frozen soil and sand as experimental samples. Firstly, 
the time it takes to reach maximum NGH breaking depth is determined. Then, the ultimate breaking distance is studied with respect to NGH saturation, jet pressure, and nozzle diameter. Following that, critical water jet breaking velocities corresponding to various sample saturations are calculated. Eventually, by combining the marine NGH strength expression with the critical breaking velocity semi-empirical formula, the formula to calculate the critical breaking velocity of marine NGH breaking by water jet is established. The characteristic velocity $(\eta)$, an undetermined coefficient in the formula, is calibrated with the experiment data. This study will be helpful for the further research on the marine NGH breakage by water jet.

\section{Experiment Equipment and Method}

\subsection{Experimemt Apparatus}

As shown in Figure 2, the experiment apparatus mainly includes a water supply tank, pump, flowmeter, pressure gauge, experimental water tank, and nozzle. The volume of the water supply tank is $4.5 \mathrm{~m}^{3}$. The pump is a plunger pump with the maximum working pressure and displacement of $30 \mathrm{MPa}$ and $200 \mathrm{~L} / \mathrm{min}$, respectively. The measuring range of pressure gauge is $0-40 \mathrm{MPa}$ at a $0.1 \mathrm{MPa}$ precision, and the measuring range of flowmeter is $2-20 \mathrm{~m}^{3} / \mathrm{h}$ at a $0.02 \mathrm{~m}^{3} / \mathrm{h}$ precision. The function of the experimental water tank is to ensure that the jet is submerged. A movable baffle is installed in the water tank between the nozzle, and the experimental sample to avoid erosion of the sample while adjusting the test pressure. The type of nozzles used in the experiment is the cone straight type. The length of the cone angle section and the straight pipe section of a nozzle are the same, which are three times of nozzle diameter. The cone angle is $13^{\circ}$.

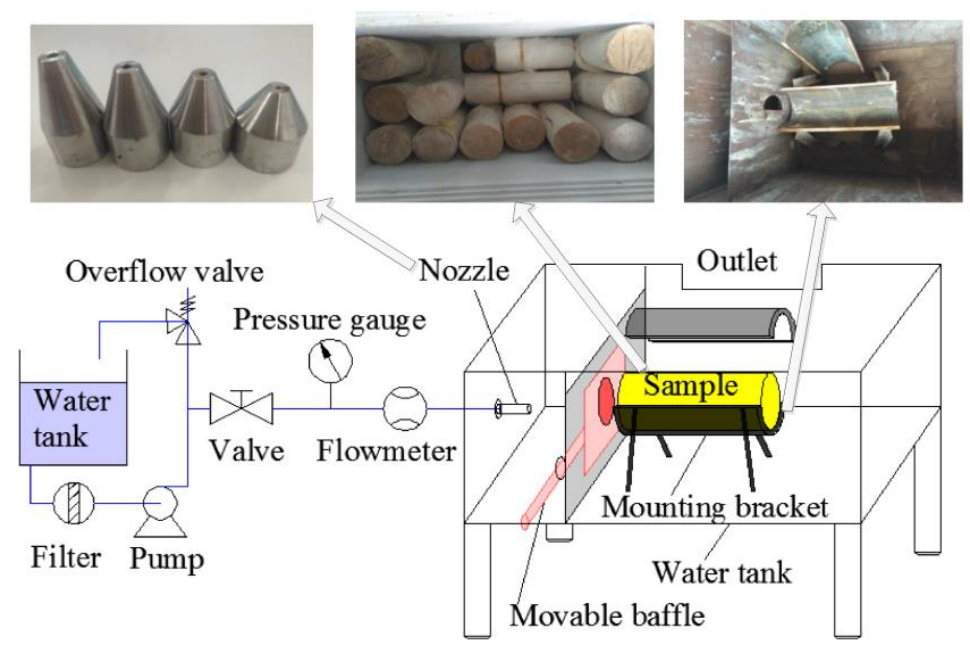

Figure 2. Schematic of the experimental system of the NGH breaking by water jet.

\subsection{Sample Preparation}

NGH is very easy to decompose at environmental temperature and pressure [25]. So, frozen sand and clay is used to instead of an NGH sediment as an experimental sample. In the early stage, it was generally believed that the mechanical properties of hydrate were similar to those of ice [26,27]. With the development of research, there are now different views on whether the mechanical properties of hydrate and ice, and the mechanical properties of hydrate sediment and frozen soil and sand, are the same. Stern [28] found that ice ordinarily exhibits a strength maximum before leveling off to steady flow stress, and methane hydrate exhibits monotonic work hardening (or strain hardening). Although the studies of Durham [29] have shown that methane hydrate is as much as 40 times stronger than ice, there is evidence that the tensile stress of methane hydrate was almost equal to that of ice, and the compressive stress was slightly higher than that of ice [30]. As for hydrate deposits and frozen soils, 
their differences mainly lie in the cohesion, while the internal friction angle is almost the same [31]. Winters [32] suggested that when porosity and saturation of the frozen soil (sand) and the NGH sediment are the same, their mechanical properties are consistent. Although the mechanical properties of frozen sand and clay are not exactly the same as that of NGH sediment, it can replace NGH sediment as an experimental sample to some extent. The experimental sample preparation is based on the matrix particle composition of NGH sediment samples in Shenhu area of South China Sea, which consists of clay $(26.89 \%)$, silty sand $(67.99 \%)$, and fine sand $(5.12 \%)$. Porosity of the NGH core sample in the Shenhu area of South China Sea is $43.6 \%$, and its matrix specific gravity is 2.7 [33]. Clay, silt, sand, and fine sand were blended uniformly in the same composition as that of the NGH sediments, to prepare the matrix sample. The mass of water can be calculated according to the following formula:

$$
\frac{m_{w}}{m_{s}}=\frac{\xi}{1-\xi} \cdot \frac{\rho_{w}}{\rho_{s}} S_{u} \varepsilon
$$

where: $m_{w}$ is mass of water; $m_{s}$ is mass of matrix; $S_{u}$ is NGH saturation; $\xi$ is porosity; $\rho_{\mathrm{w}}$ is density of water; $\rho_{\mathrm{S}}$ is density of matrix; $\varepsilon$ is volume ratio of ice to water-because of the volume expansion of water during freezing, its value is 1.1.

For the experimental samples with saturation of $20 \%, 40 \%, 60 \%$, and $80 \%$, the mass ratio of water to matrix is $5.2 \%, 10.4 \%, 15.6 \%$, and $20.8 \%$, respectively. Evenly mixed water and matrix was poured into molds and frozen at $-18{ }^{\circ} \mathrm{C}$ for seven days, after which the experiment samples were prepared.

\subsection{Experimemt Procedure}

A few hours before the start of the experiment, sufficient ice was added into the experimental water tank and water supply tank, to ensure the low temperature of experiment sample and jet water. Relative positions of the nozzle and the experimental sample were adjusted, so that they were on the same axis with a $20 \mathrm{~mm}$ distance. Prior to turning on the pump, the movable baffle was kept closed. The pump was turned on and the jet pressure was adjusted. When the jet pressure reached the experimental set point, the removable baffle was lifted to the open position, and the NGH water jet breaking experiment was timed as started. Every certain time duration, the removable baffle was closed to pause the jet breaking, and to record the jet breaking depth (the depth of the experimental sample that the water jet had broken into). When the jet breaking depth did not increase any more, an experiment of NGH jet water breaking was considered as completed. As shown in Table 1, a total of sixteen groups of orthogonal design experiments were designed and conducted with a variation of nozzle diameter, jet pressure, and NGH saturation.

Table 1. Orthogonal design experimental parameters of NGH breaking by water jet.

\begin{tabular}{cccc}
\hline Experimental Serial Number & Saturation (\%) & Nozzle Diameter $(\mathbf{m m})$ & Jet Pressure (MPa) \\
\hline 1 & 20 & 1.5 & 2.5 \\
2 & 20 & 2.0 & 5 \\
3 & 20 & 2.5 & 7.5 \\
4 & 20 & 3.0 & 10 \\
5 & 40 & 1.5 & 5 \\
6 & 40 & 2.0 & 2.5 \\
7 & 40 & 2.5 & 10 \\
8 & 40 & 3.0 & 7.5 \\
9 & 60 & 1.5 & 7.5 \\
10 & 60 & 2.0 & 10 \\
11 & 60 & 2.5 & 2.5 \\
12 & 60 & 3.0 & 5 \\
13 & 80 & 1.5 & 10 \\
14 & 80 & 2.0 & 7.5 \\
15 & 80 & 2.5 & 5 \\
16 & 80 & 3.0 & 2.5 \\
\hline
\end{tabular}




\section{Results and Discussion}

\subsection{Ultimate Breaking Time of the NGH Water Jet Breaking Process}

For each jet breaking experiment, the sample breakage depth when the jet water could not break into the experiment sample any further is defined as maximum breaking depth. The time it takes to achieve the maximum breaking depth is the ultimate breaking time. Since the experimental sample is made of frozen soil, although the sample is submerged in the water tank to maintain low temperature, it should not be exposed to above zero degrees centigrade ambience for an excessive time. During the jet breaking process, the major breakage happens in the early stage for a short period of time, and, as the jet breaking proceeds, the breaking rate becomes low and breaking depth changes very little. Therefore, based on the correlation of breaking depth and time, the breaking depth that barely changes with time is approximately regarded as the maximum breaking depth, and the corresponding time is considered the ultimate breaking time. Figure 3 shows the variation of breaking depth with breaking time under various experimental conditions. As the jet breaking process proceeds, breaking depth increases with time, and breaking depth increase slows down with time. The first $0-15 \mathrm{~s}$ is the fast-breaking section, during which breaking depth increases rapidly. The following 16-63 s is the slow-breaking section during which breaking depth increases slowly. Comparing the breaking depth and time correlations under three experimental conditions in Figure 3, it was found that, given the same jet breaking time, the larger the breaking depth, the more significant breaking depth increases during the slow-breaking section, so a longer breaking time is needed to achieve the maximum breaking depth. Among all the NGH jets breaking experimental conditions, sample saturation of $20 \%$ (lowest), jet pressure of $10 \mathrm{MPa}$ (highest), and nozzle diameter of $3.0 \mathrm{~mm}$ (largest) lead to the largest breaking depth, and thus results in the longest ultimate breaking time. Under this experimental condition $\left(S_{\mathrm{n}}=20 \%, P=10 \mathrm{MPa}\right.$, $D_{\mathrm{n}}=3.0 \mathrm{~mm}$ ), average breaking rate (the rate of breaking depth increase is defined as breaking rate) during the fast-breaking section is $18.6 \mathrm{~mm} / \mathrm{s}$, and the average breaking rate of the slow-breaking section is as low as $1.4 \mathrm{~mm} / \mathrm{s}$. Breaking rate slows down further after the slow-breaking section, so the breaking depth increase after slow-breaking section is negligible. Therefore, based on the breaking depth vs. time curve of the experiment under sample saturation of $20 \%$, jet pressure of $10 \mathrm{MPa}$, and nozzle diameter of $3.0 \mathrm{~mm}, 63 \mathrm{~s}$ is considered ultimate breaking time. The jet breaking process is conducted for $63 \mathrm{~s}$ for the following experiments.

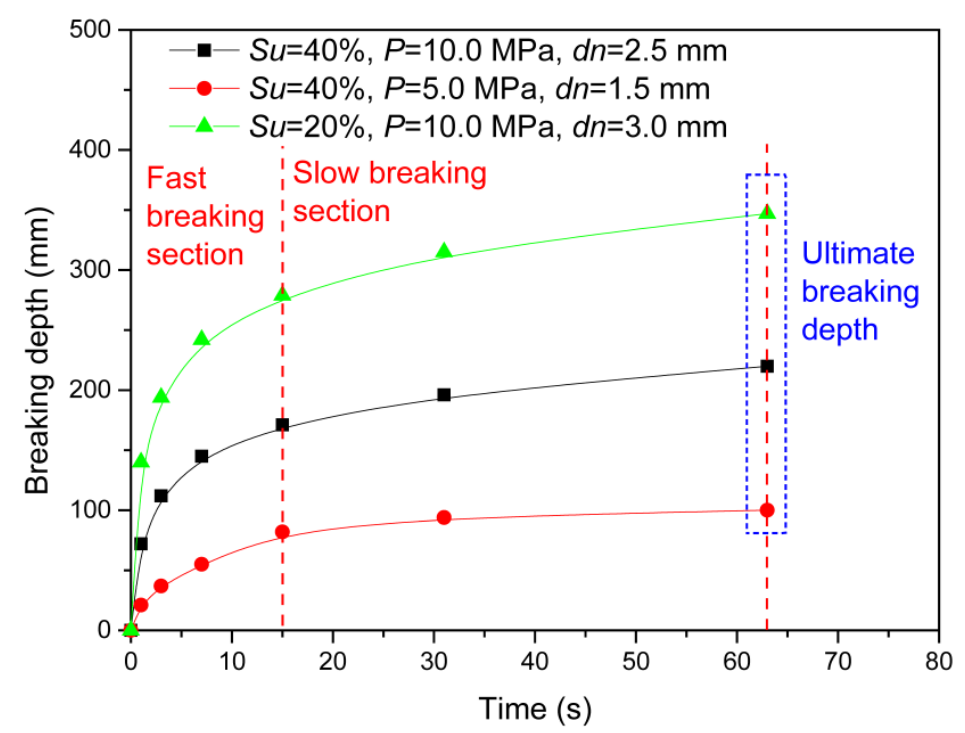

Figure 3. Variation of breaking depth with jetting time of water jet on NGH. 


\subsection{Ultimate Breaking Distance of NGH Breaking by Water Jet}

Ultimate breaking distance, the summation of the target distance (the initial distance between the nozzle and the experimental sample prior to the NGH water jet breaking process, $20 \mathrm{~mm}$ ) and the maximum breaking depth, is an important parameter to determine the critical water jet breaking velocity. Figure $4 a, d$ shows the variation of the ultimate breaking distance with nozzle diameter and jet pressure when the sample saturation was $20 \%, 40 \%, 60 \%$, and $80 \%$ respectively. The average ultimate breaking distances corresponding to $20 \%, 40 \%, 60 \%$, and $80 \%$ sample saturations were $230.5 \mathrm{~mm}$, $179 \mathrm{~mm}, 126.5 \mathrm{~mm}$, and $109.25 \mathrm{~mm}$, respectively, which suggests that the higher sample saturation, the shorter the ultimate breaking distance.

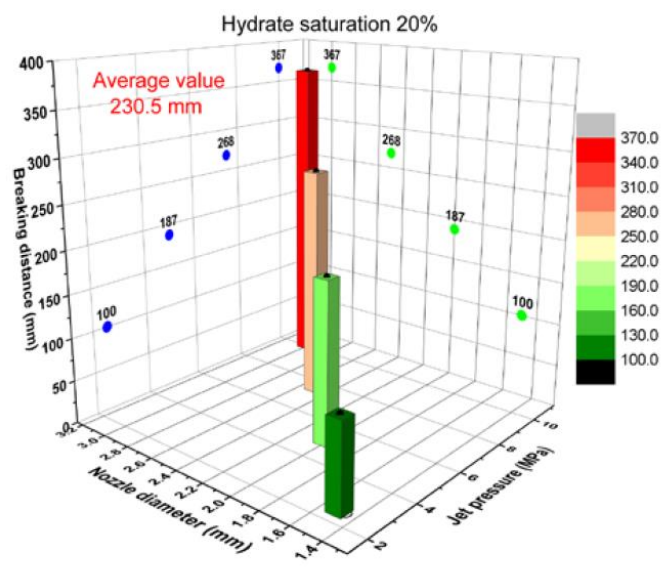

(a)

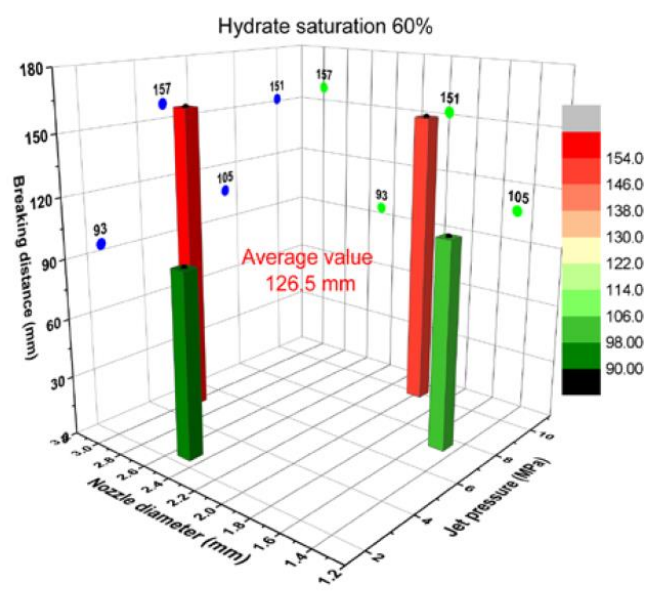

(c)

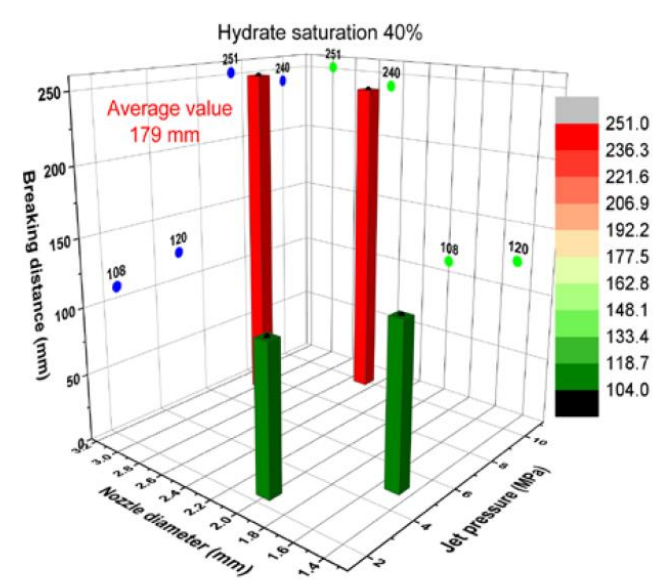

(b)

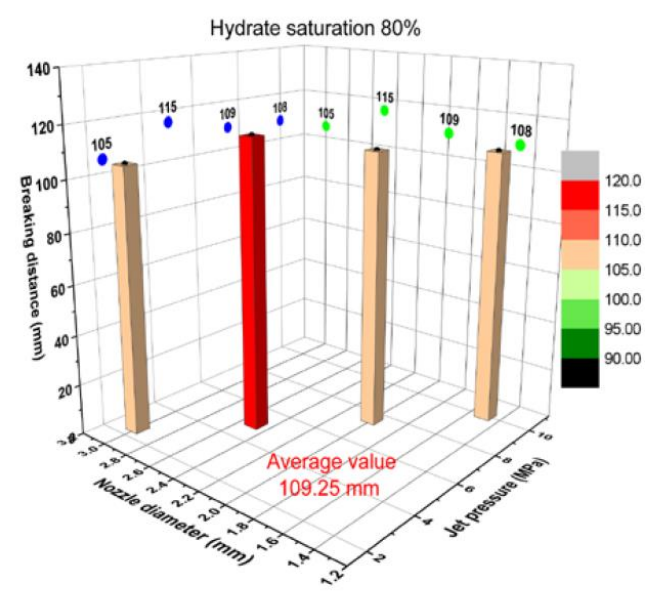

(d)

Figure 4. Variation of the breaking distances with nozzle diameter and jet pressure at various NGH saturations: (a) NGH saturation is $20 \%$. (b) NGH saturation is $40 \%$. (c) NGH saturation is $60 \%$. (d) NGH saturation is $80 \%$.

In orthogonal design test analysis, the range of a certain factor indicates the variation of the factor. A larger range indicates a higher influence that the specific factor has on the experimental index. As an example, the ultimate distance range of the sample saturation was calculated as the highest average ultimate distance $(230.5 \mathrm{~mm})$ among those corresponding to four various sample saturations, minus the lowest average ultimate distance $(109.25 \mathrm{~mm})$, equaling $121.25 \mathrm{~mm}$. The ultimate breaking distance ranges of nozzle diameter and jet pressure were calculated using the same method, as shown in Table 2. In Table 2, $K i$ indicates the average ultimate breaking distance corresponding to Experiment Level $i$. Table 2 shows that the average ultimate breaking distance $K i$ increases with nozzle diameter 
and jet pressure increase. The average ultimate breaking distance ranges of the three experimental factors, sample saturation, jet pressure, and nozzle diameter, were $121.25 \mathrm{~mm}, 115 \mathrm{~mm}$, and $112.5 \mathrm{~mm}$, respectively. This shows that the sample saturation has the greatest effect on ultimate breaking distance. However, NGH saturation is a sediment property that could not be changed artificially. In summary, the three factors in order of the effect on the ultimate breaking depth (from high to low) are sample saturation, jet pressure, and nozzle diameter. There is a limitation in this orthogonal design experiment. Although the influence of a single parameter on the ultimate breaking depth is analyzed, the influence of interaction parameters on the ultimate breaking depth are not considered. The latter can more clearly reveal the relationship between the ultimate breaking distance and the experimental parameters. The main reason is that the main goal of this paper is to study the critical velocity of NGH sediment, which is a parameter to characterize the natural characteristics of NGH sediment. So, the critical velocity of NGH sediment is independent of jet pressure and nozzle diameter. Therefore, the interaction study is not considered in this orthogonal design experiment.

Table 2. Range analysis table of orthogonal design experiment.

\begin{tabular}{cccc}
\hline \multirow{2}{*}{ Parameter } & Factor A & Factor B & Factor C \\
\cline { 2 - 4 } & Saturation & Jet Pressure & Nozzle Diameter \\
\cline { 2 - 4 } & $230.5(20 \%)$ & $101.5(2.5 \mathrm{MPa})$ & $107.5(1.5 \mathrm{~mm})$ \\
$K_{1}$ & $179(40 \%)$ & $144(5.0 \mathrm{MPa})$ & $138.75(2.0 \mathrm{~mm})$ \\
$K_{2}$ & $126.5(60 \%)$ & $183.25(7.5 \mathrm{MPa})$ & $179(2.5 \mathrm{~mm})$ \\
$K_{3}$ & $109.25(80 \%)$ & $216.5(10.0 \mathrm{MPa})$ & $220(3.0 \mathrm{~mm})$ \\
$K_{4}$ & 121.25 & 115 & 112.5 \\
$R$ & & & \\
\hline
\end{tabular}

\subsection{Critical Velocity of the NGH}

The critical velocity of the NGH breakage by the water jet is the axial water jet velocity at the sample breakage cross section when the ultimate breaking distance is achieved. The water jet flow velocity can be calculated based on the attenuation equation of the jet flow field. Although the water jet flow in this study is the non-free jet inside the enclosure, its axial jet velocity follows the same attenuation law as the free jet flow [34]. For the free jet flow, the jet flow field consists of the core area where axial velocity keeps the same, and the diffusion area where axial velocity declines with distance from the nozzle. Axial velocity can be expressed as Equations (2) and (3):

When $x<x_{0}$

$$
v_{x}=v_{0}
$$

When $x>x_{0}$

$$
v_{x}=\frac{\lambda d_{n}}{x} v_{0}
$$

where: $x$ is the distance to nozzle, $x_{0}$ is the length of the potential core, $x_{0}=\lambda d_{\mathrm{n}}, v_{0}$ is the initial exit velocity of the jet, $v_{x}$ is the axial velocity of jet at distance $x$ from nozzle, $d_{\mathrm{n}}$ is the nozzle diameter, $\lambda$ is a dimensionless parameter to be measured experimentally, and Rajaratnam [35] recommends that the value of $\lambda$ is 6.3 .

Since the target distance between nozzle and experiment sample is larger than the length of the core area, the attenuation law of the axial velocity in the diffusion area, Equation (3), applies to velocity calculation for this study. As defined, when jet distance $x$ increases to the ultimate breaking distance, the corresponding axial jet velocity is the critical water jet breaking velocity of the NGH breakage by the water jet process. Figure $5 \mathrm{a}-\mathrm{d}$ shows the variation of the critical water jet breaking velocities with nozzle diameter and jet pressure when the sample saturations were $20 \%, 40 \%, 60 \%$, and $80 \%$, respectively. With the same sample saturation, experiments conducted under various jet pressures and nozzle diameters have almost the same critical water jet breaking velocity, which implies that critical velocity is a feature of the broken object, in this case NGH or the experimental sample, and 
is not affected by jet flow parameters. With the increase in the sample saturation, average critical velocity under various jet pressures and nozzle diameters increases. Average critical water jet velocities corresponding to the sample saturation of $20 \%, 40 \%, 60 \%$, and $80 \%$ are $5.71 \mathrm{~m} / \mathrm{s}, 7.14 \mathrm{~m} / \mathrm{s}, 9.60 \mathrm{~m} / \mathrm{s}$, and $10.85 \mathrm{~m} / \mathrm{s}$, respectively.

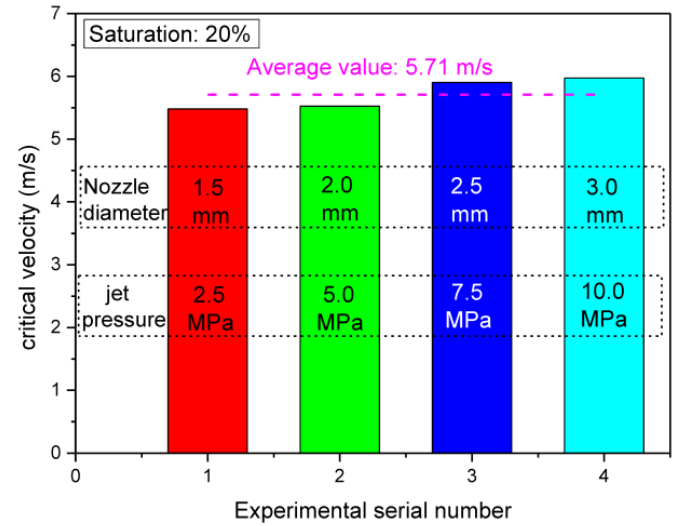

(a)

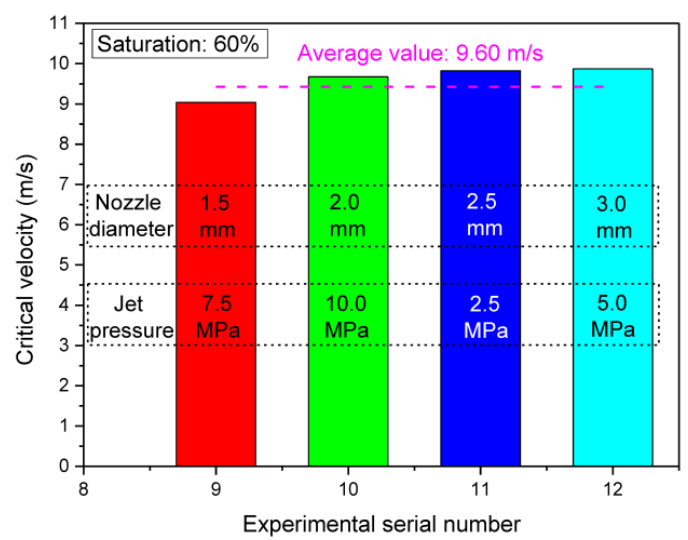

(c)

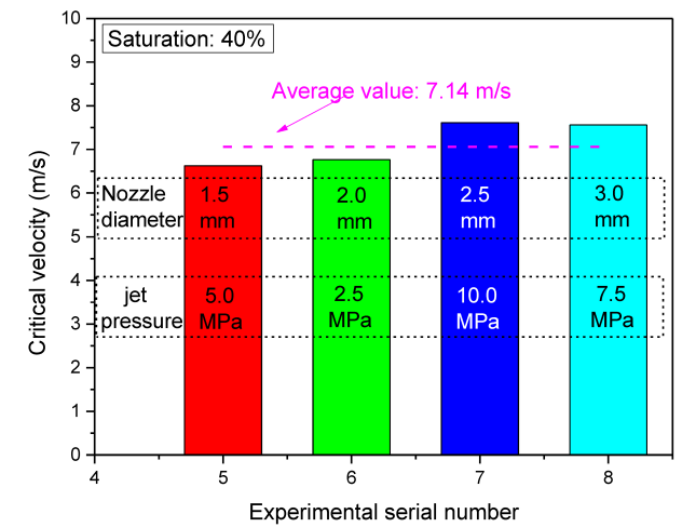

(b)

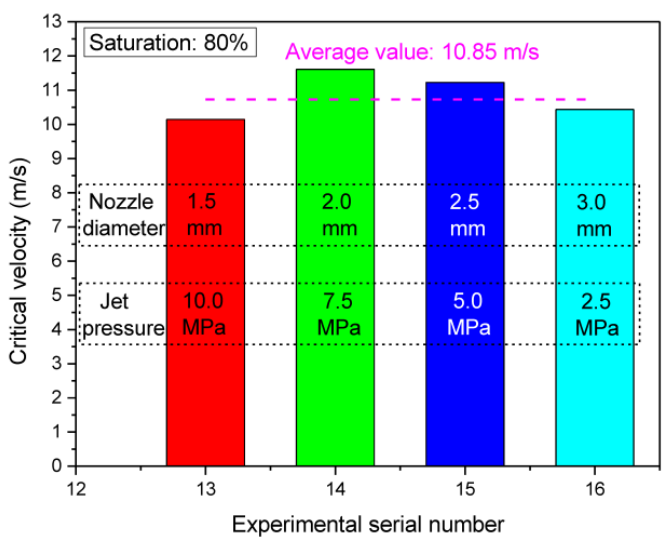

(d)

Figure 5. Variation of the critical breaking velocities with nozzle diameter and jet pressure under various NGH saturations: (a) NGH saturation is $20 \%$. (b) NGH saturation is $40 \%$. (c) NGH saturation is $60 \%$. (d) NGH saturation is $80 \%$. The different colors red, green, dark blue and light blue in the figure indicate that the nozzle diameters are $1.5 \mathrm{~mm}, 2.0 \mathrm{~mm}, 2.5 \mathrm{~mm}$ and $3.0 \mathrm{~mm}$ respectively.

To further theoretically analyze the correlation between critical velocity of NGH and NGH saturation, the critical breaking velocity formula established by Dabbagh [36] was introduced as Equations (4):

$$
v_{c r}=\eta\left(\frac{q_{u}}{p_{a t m}}\right)^{k}
$$

where: $\eta$ is a characteristic velocity, whose value equals to the critical velocity when the strength of NGH sediment is equal to the atmospheric pressure, $\eta$ needs to be measured experimentally, $k$ is a dimensionless exponent, its value is $0.5, P_{a t m}$ is atmospheric pressure, $v_{c r}$ is critical velocity, $q_{u}$ is uniaxial compressive strength.

Because NGH sediment decomposes under normal pressure and temperature, its uniaxial compressive strength cannot be measured directly. Therefore, the expression of uniaxial compressive strength of NGH sediment is derived from maximum deviator stress, which is fitted with triaxial test 
data. Kuniyuki [37] recommends that maximum deviator stress of NGH sediment can be calculated by the following formula:

$$
q_{f}=\frac{2 \cdot \cos \varphi}{1-\sin \varphi} c_{0}+\alpha S_{h}^{\beta}+\frac{2 \cdot \sin \varphi}{1-\sin \varphi} \sigma_{3}
$$

where: $q_{f}$ is maximum deviator stress of NGH sediment, in $\mathrm{MPa}$; $\varphi$ is the internal friction angle, $33.8^{\circ}$; $c_{0}$ is cohesion, $0.3 \mathrm{MPa} ; \sigma_{3}$ is the effective confining pressures, in $\mathrm{MPa} ; \alpha$ and $\beta$ are undetermined parameters, whose values are $4.64 \times 10^{-3}$ and 1.58 , respectively.

Regardless of the effective confining pressure, the uniaxial compressive strength of NGH sediment is equal to triaxial compressive strength, and its expression can be written as:

$$
q_{u}=q_{f\left(\sigma_{3}=0\right)}=\frac{2 \cdot \cos \varphi}{1-\sin \varphi} c_{0}+\alpha S_{h}^{\beta}
$$

Combining Equations (4) and (6), the formula for critical velocity of NGH sediment calculation was obtained:

$$
v_{c r}=\eta\left[\frac{1}{p_{\text {atm }}} \cdot\left(\frac{2 \cdot \cos \varphi}{1-\sin \varphi} c_{0}+\alpha S_{h}^{\beta}\right)\right]^{0.5}
$$

Substituting the experimental data to Equation (7), the characteristic velocity $\eta$ was calculated, as shown in Figure 6. Corresponding to the NGH saturation of $20 \%, 40 \%, 60 \%$, and $80 \%$, $\eta$ was calculated to be $1.41 \mathrm{~m} / \mathrm{s}, 1.39 \mathrm{~m} / \mathrm{s}, 1.52 \mathrm{~m} / \mathrm{s}$, and $1.44 \mathrm{~m} / \mathrm{s}$, respectively. Values of $\eta$ calculated with various saturations are close, which proves that the critical water jet velocity formula is correct. Average critical water jet velocity under various saturations is $1.44 \mathrm{~m} / \mathrm{s}$.

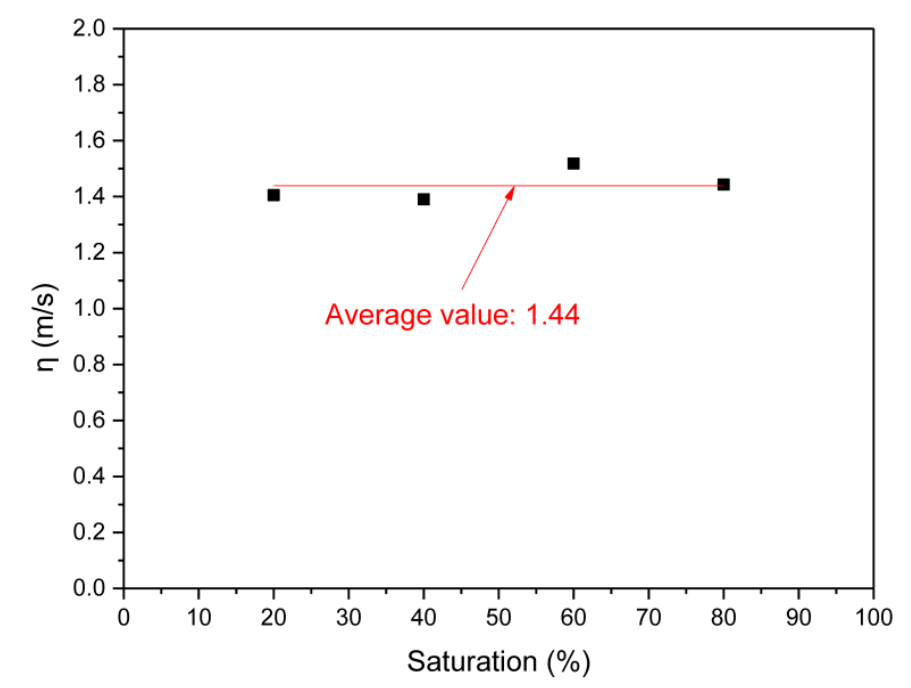

Figure 6. The relationship between the characteristic velocity $\eta$ and the NGH saturation.

\section{Conclusions}

Based on the experimental and theoretical analysis, the critical water jetting breaking velocity for marine NGH breakage by water jet process was studied. Under various experimental conditions, the deeper the NGH breakage achieved through water jetting process, the greater the breaking ability of the water jet flow is within the same time, and therefore it takes longer to achieve the maximum breaking depth. Given the experimental conditions in this study, maximum breaking depth was achieved in $63 \mathrm{~s}$ of the NGH water jet breaking process.

Through orthogonal design experiment analysis, the ultimate breaking distance ranges of the three experimental factors, sample saturation, jet pressure, and jet nozzle diameter, were found to be $121.25 \mathrm{~mm}, 115 \mathrm{~mm}$, and $112.5 \mathrm{~mm}$ respectively. Hence, the order (from high to low) of the effect of the three factors on the ultimate breaking depth is NGH saturation, jet pressure, and jet nozzle diameter. 
Critical water jet breaking velocity of NGH breakage by the water jetting process was found to increase with NGH saturation increase. Average critical water jetting velocities corresponding with NGH saturations of $20 \%, 40 \% 60 \%$, and $80 \%$ were $5.71 \mathrm{~m} / \mathrm{s}, 7.14 \mathrm{~m} / \mathrm{s}, 9.60 \mathrm{~m} / \mathrm{s}$, and $10.85 \mathrm{~m} / \mathrm{s}$, respectively. The formula was established to calculate the critical water jet breaking velocity of the marine NGH breakage by water jet process. Using the experiment data, the undetermined coefficient $\eta$ in the critical water jet breaking velocity equation was calibrated to be $1.44 \mathrm{~m} / \mathrm{s}$. Considering that frozen clay and sand are used instead of NGH sediment as the experimental samples in the experiment, there will be some errors in this value $\eta$ for real NGH sediment, which should be considered in practical engineering applications.

Author Contributions: Conceptualization, G.W.; Data curation, L.W.; Formal analysis, G.W.; Funding acquisition, G.W.; Investigation, G.W.; Methodology, L.W.; Project administration, G.W.; Resources, L.W.; Validation, L.W.; Writing—original draft, L.W.; Writing—review \& editing, G.W. All authors have read and agreed to the published version of the manuscript.

Funding: National Key R\&D Program of China, grant number 2016YFC0304008. National Key R\&D Program of China, grant number 2018YFC0310201. Strategic Consultation Project of the Chinese Academy of Engineering, grant number 2017-XZ-10-02-02.

Conflicts of Interest: The authors declare no conflict of interest.

\section{References}

1. Makogon, Y.F. Natural gas hydrates-A promising source of energy. J. Nat. Gas. Sci. Eng. 2010, 2, 49-59. [CrossRef]

2. Chong, Z.R.; Yang, S.H.B.; Babu, P.; Linga, P.; Li, X.-S. Review of natural gas hydrates as an energy resource: Prospects and challenges. Appl. Energy 2016, 162, 1633-1652. [CrossRef]

3. Boswell, R.; Collett, T.S. Current perspectives on gas hydrate resources. Energy Env. Sci. 2011, 4, 1206-1215. [CrossRef]

4. Pinero, E.; Marquardt, M.; Hensen, C.; Haeckel, M.; Wallmann, K. Estimation of the global inventory of methane hydrates in marine sediments using transfer functions. Biogeosciences 2013, 10, 959-975. [CrossRef]

5. Boswell, R.; Collett, T. The Gas Hydrates Resource Pyramid: Fire in the ice, methane hydrate newsletter. US Dep. Energy 2006, 6, 5-7.

6. Tamaki, M.; Fujii, T.; Suzuki, K. Characterization and Prediction of the Gas Hydrate Reservoir at the Second Offshore Gas Production Test Site in the Eastern Nankai Trough, Japan. Energies 2017, 10, 1678. [CrossRef]

7. Konno, Y.; Fujii, T.; Sato, A.; Akamine, K.; Naiki, M.; Masuda, Y.; Yamamoto, K.; Nagao, J. Key Findings of the World's First Offshore Methane Hydrate Production Test off the Coast of Japan: Toward Future Commercial Production. Energy Fuels 2017, 31, 2607-2616. [CrossRef]

8. Arata, N.; Sukizaki, S.; Denda, A.; Awashima, Y.; Okada, Y. Overview of the R\&D for an Environmental Impact Assessment on Japan's Methane Hydrate R\&D Program in Phase-1. J. Jpn. Assoc. Pet. Technol. 2009, 74, 350-359.

9. Wu, X.H.W.; Liu, W. Assessment of global gas hydrate resource potential and progress of production. Mar. Geol. Front. 2018, 33, 63-78.

10. Li, H.; Wei, N.; Jiang, L.; Zhao, J.; Cui, Z.; Sun, W.; Zhang, L.; Zhou, S.; Xu, H.; Zhang, X.; et al. Evaluation of Experimental Setup and Procedure for Rapid Preparation of Natural Gas Hydrate. Energies 2020, 13, 531. [CrossRef]

11. Wu, S.W.J. Reflections on the Successful Trial Production of Natural Gas Hydrate in Shenhu Sea Area of South China Sea. Chin. Sci. Bull. 2018, 63, 2-8. [CrossRef]

12. Li, G.; Moridis, G.J.; Zhang, K.; Li, X.-S. Evaluation of Gas Production Potential from Marine Gas Hydrate Deposits in Shenhu Area of South China Sea. Energy Fuels 2010, 24, 6018-6033. [CrossRef]

13. Moridis, G.; Reagan, M.T.; Boyle, K.L.; Zhang, K. Evaluation of the Gas Production Potential of Some Particularly Challenging Types of Oceanic Hydrate Deposits. Transp. Porous Media 2011, 90, 269-299. [CrossRef]

14. Zhou, S.C.W.; Li, Q. Research on the solid fluidization well testing and production for shallow non-diagenetic natural gas hydrate in deep water area. China Offshore Oil Gas. 2017, 29, 1-8. 
15. Wu, X.; Liang, Q.; Ma, Y.; Shi, Y.; Xia, Z.; Liu, L.; Haeckel, M. Submarine Landslides and their Distribution in the Gas Hydrate Area on the North Slope of the South China Sea. Energies 2018, 11, 3481. [CrossRef]

16. First successful trial collection of natural gas hydrate in China. Geol. China 2017, 44, 620-621.

17. Qiu, S.; Wang, G.; Wang, L.; Fang, X. A Downhole Hydrocyclone for the Recovery of Natural Gas Hydrates and Desanding: The CFD Simulation of the Flow Field and Separation Performance. Energies 2019, 12, 3257. [CrossRef]

18. Zhou, S.; Chen, W.; Li, Q. Green production technology of deep water shallow gas hydrate with solid fluidization method. China Offshore Oil Gas. 2014, 26, 1-7.

19. Pan, D.C.C.; Yang, L.; Jin, C.; Li, X.; Liu, S.; Chen, Y.; Zhu, J. Physical simulation experiment system for jet erosion of natural gas hydrate. Explor. Eng. Rock Soil Drill. Tunn. 2018, 45, 35-39.

20. Chen, C.; Pan, D.; Yang, L.; Zhang, H.; Li, B.; Jin, C.; Li, X.; Cheng, Y.; Zhong, X. Investigation into the Water Jet Erosion Efficiency of Hydrate-Bearing Sediments Based on the Arbitrary Lagrangian-Eulerian Method. Appl. Sci. 2019, 9, 182. [CrossRef]

21. Yang, L. Study on the Breaking Process of Marine Hydrate Subjected to High Pressure Water Jet and the Production Increase of Marine Hydrate Reservoirs Reconstruction; Jilin University: Changchun, China, 2018.

22. Wang, G.; Zhong, L.; Zhou, S.; Liu, Q.; Li, Q.; Fu, Q.; Wang, L.; Huang, R.; Wang, G.; Li, X. Jet breaking tools for natural gas hydrate exploitation and their support technologies. Nat. Gas. Ind. B 2018, 5, 312-318. [CrossRef]

23. Wang, G.; Huang, R.; Zhong, L.; Wang, L.; Zhou, S.; Liu, Q. An optimal design of crushing parameters of marine gas hydrate reservoirs in solid fluidization exploitation. Nat. Gas. Ind. B 2019, 6, 257-261. [CrossRef]

24. Wang, L.; Wang, G.; Mao, L.; Zhou, S.; Zhong, L. Experimental research on the breaking effect of natural gas hydrate sediment for water jet and engineering applications. J. Pet. Sci. Eng. 2020, 184, 106553. [CrossRef]

25. Lv, X.; Shi, B.; Zhou, S.; Wang, S.; Huang, W.; Sun, X. Study on the Decomposition Mechanism of Natural Gas Hydrate Particles and Its Microscopic Agglomeration Characteristics. Appl. Sci. 2018, 8, 2464. [CrossRef]

26. Dvorkin, J.; Helgerud, M.B.; Waite, W.; Kirby, S.H.; Nur, A. Introduction to Physical Properties and Elasticity Models. In Asia-Pacific Coasts and Their Management; Springer Science and Business Media LLC: Berlin/Heidelberg, Germany, 2003; Volume 5, pp. 245-260.

27. Cox, J.L. Natural Gas. Hydrates: Properties, Occurrence and Recovery; US Department of Energy: Washington, DC, USA, 1983.

28. Stern, L.A.; Kirby, S.H.; Durham, W.B. Polycrystalline Methane Hydrate: Synthesis from Superheated Ice, and Low-Temperature Mechanical Properties. Energy Fuels 1998, 12, 201-211. [CrossRef]

29. Durham, W.B.; Stern, L.A.; Kirby, S.H. Ductile flow of methane hydrate. Can. J. Phys. 2003, 81, 373-380. [CrossRef]

30. Cao, P.; Wu, J.; Zhang, Z.; Fang, B.; Ning, F. Mechanical Properties of Methane Hydrate: Intrinsic Differences from Ice. J. Phys. Chem. C 2018, 122, 29081-29093. [CrossRef]

31. Zhang, X.; Wang, S.; Li, Q.; Zhao, J.; Wang, A. Experimental study of mechanical properties of gas hydrate deposits. Rock Soil Mech. 2010, 31, 3069-3074.

32. Winters, W.; Pecher, I.A.; Waite, W.; Mason, D.H. Physical properties and rock physics models of sediment containing natural and laboratory-formed methane gas hydrate. Am. Min. 2004, 89, 1221-1227. [CrossRef]

33. Kuang, Y.; Yang, L.; Li, Q.; Lv, X.; Li, Y.; Yu, B.; Leng, S.; Song, Y.; Zhao, J. Physical characteristic analysis of unconsolidated sediments containing gas hydrate recovered from the Shenhu Area of the South China sea. J. Pet. Sci. Eng. 2019, 181, 106173. [CrossRef]

34. Ho, C.E. Turbulent Fluid Jet Excavation in Cohesive Soil: With Particular Application to Jet Grouting; Massachusetts Institute of Technology: Cambridge, MA, USA, 2005.

35. Rajaratnam, N. Turbulent Jets. Dev. Water Sci. 1976, 5, 77-82.

36. Dabbagh, A.A.; Gonzalez, A.S.; Pena, A.S. Soil Erosion by a Continuous Water Jet. Soils Found 2002, 42, 1-13. [CrossRef]

37. Miyazaki, K.; Temma, N.; Aoki, K.; Yamaguchi, T. A Nonlinear Elastic Model for Triaxial Compressive Properties of Artificial Methane-Hydrate-Bearing Sediment Samples. Energies 2012, 5, 4057-4075. [CrossRef] 